University of Nebraska - Lincoln

DigitalCommons@University of Nebraska - Lincoln

\title{
Current status and future directions of precision aerial application for site-specific crop management in the USA
}

\author{
Yubin Lan \\ USDA-ARS-SPARC, College Station, TX, yubin.lan@ars.usda.gov \\ Steven J. Thomson \\ USDA-ARS \\ Yanbo Huang \\ USDA-ARS
}

W. Clint Hoffmann

USDA-ARS

Huihui Zhang

Texas A\&M University

Follow this and additional works at: https://digitalcommons.unl.edu/usdaarsfacpub

Lan, Yubin; Thomson, Steven J.; Huang, Yanbo; Hoffmann, W. Clint; and Zhang, Huihui, "Current status and future directions of precision aerial application for site-specific crop management in the USA" (2010). Publications from USDA-ARS / UNL Faculty. 2082.

https://digitalcommons.unl.edu/usdaarsfacpub/2082

This Article is brought to you for free and open access by the U.S. Department of Agriculture: Agricultural Research Service, Lincoln, Nebraska at DigitalCommons@University of Nebraska - Lincoln. It has been accepted for inclusion in Publications from USDA-ARS / UNL Faculty by an authorized administrator of DigitalCommons@University of Nebraska - Lincoln. 
Review

\title{
Current status and future directions of precision aerial application for site-specific crop management in the USA
}

\author{
Yubin Lan ${ }^{\mathrm{a}, *}$, Steven J. Thomson ${ }^{\mathrm{b}}$, Yanbo Huang ${ }^{\mathrm{b}}$, W. Clint Hoffmann ${ }^{\mathrm{a}}$, Huihui Zhang ${ }^{\mathrm{c}}$ \\ a USDA, ARS, Areawide Pest Management Research Unit (APMRU), 2771 F \& B Road, College Station, TX 77845, USA \\ b United States Department of Agriculture (USDA), Agricultural Research Service (ARS), Crop Production Systems Research Unit (CPSRU), Stoneville, MS, USA \\ ${ }^{\mathrm{c}}$ Department of Bio. and Agric. Engineering, Texas AE'M University, College Station, TX, USA
}

\section{A R T I C L E I N F O}

\section{Article history:}

Received 17 November 2009

Received in revised form 4 June 2010

Accepted 6 July 2010

\section{Keywords:}

Precision agriculture

Site-specific management

Remote sensing

GPS/GIS

Variable-rate aerial application

\begin{abstract}
A B S T R A C T
The first variable-rate aerial application system was developed about a decade ago in the USA and since then, aerial application has benefitted from these technologies. Many areas of the United States rely on readily available agricultural airplanes or helicopters for pest management, and variable-rate aerial application provides a solution for applying field inputs such as cotton growth regulators, defoliants, and insecticides. In the context of aerial application, variable-rate control can simply mean terminating spray over field areas that do not require inputs, terminating spray near pre-defined buffer areas determined by Global Positioning, or applying multiple rates to meet the variable needs of the crop. Prescription maps for aerial application are developed using remote sensing, Global Positioning, and Geographic Information System technologies. Precision agriculture technology has the potential to benefit the agricultural aviation industry by saving operators and farmers time and money.
\end{abstract}

Published by Elsevier B.V.

\section{Contents}

1. Introduction.

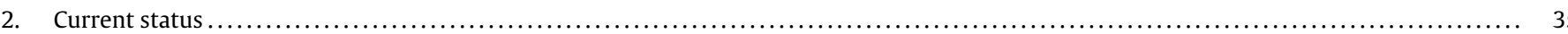

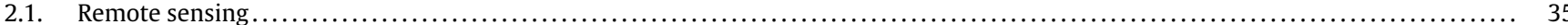

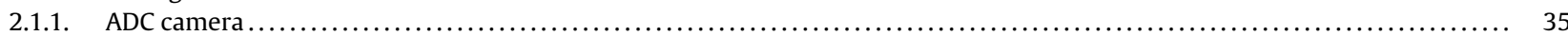

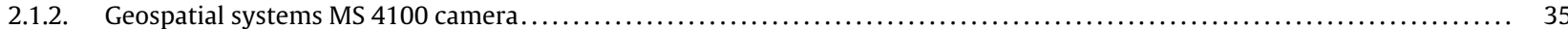

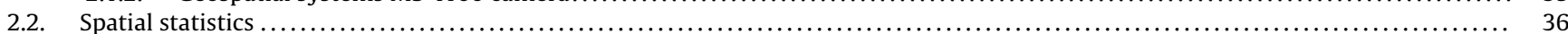

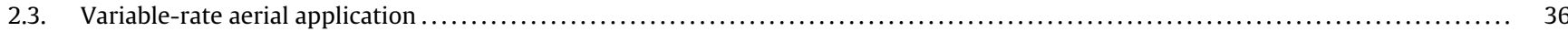

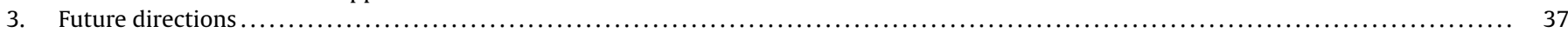

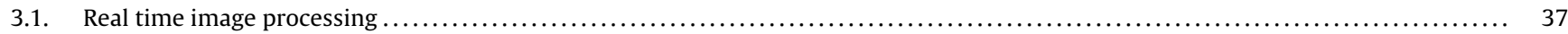

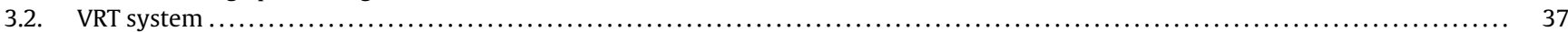

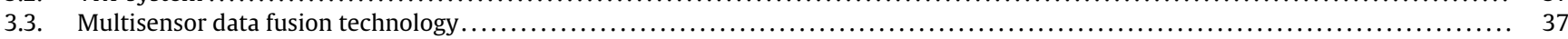

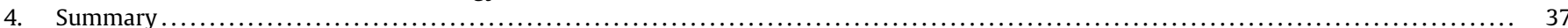

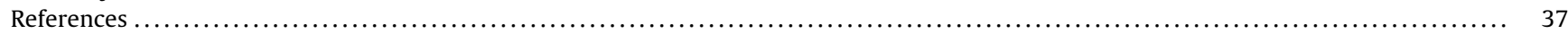

\section{Introduction ${ }^{1}$}

Aerial application, commonly called crop dusting, involves spraying crops with fertilizers, pesticides, fungicides, and other crop protection materials from agricultural aircraft. Precision

\footnotetext{
* Corresponding author. Tel.: +1979 2603759.

E-mail address: Yubin.Lan@ars.usda.gov (Y. Lan).

1 Mention of trademark, vendor, or proprietary product does not constitute a guarantee or warranty of the product by the USDA and does not imply its approval to the exclusion of other products that may also be suitable.
}

agriculture includes various technologies that allow agricultural professionals to use information management tools to optimize agriculture production. The new technologies allow aerial applicators to improve application accuracy and efficiency. It has been about a decade since development of the first variable-rate aerial application system. Many areas of the United States rely on readily available agricultural airplanes or helicopters for pest management. Several types of precision agriculture technologies that assist aerial applicators include global positioning system (GPS), geographic information system (GIS), soil mapping, yield monitoring, nutrient management field mapping, aerial photography, variable-rate controllers, and new types of nozzles such as pulse width mod- 
ulation and variable-rate nozzles. Variable-rate aerial application provides a solution for applying field inputs such as cotton growth regulators, defoliants, and insecticides. Prescription maps for aerial application have been developed using remote sensing and GPS/GIS technologies. Precision agriculture technology has the potential to benefit the agricultural aviation industry by saving operators and farmers time and money.

Airborne remote sensing may also benefit aerial applicators by creating a new revenue source because agricultural aircraft are easier to schedule for frequent remote sensing missions that would coincide with aerial spray applications. An airborne remote sensing system produces precise images for spatial analyses of plant stress due to water or nutrient status in the field, disease, and pest infestations. However, natural variations in biological characteristics, presence of disease and insects, and the interactions among these factors combine to influence crop quality and yield. Spatial statistics can often increase understanding of the field and plant conditions. Through image processing, remote sensing data are converted into prescription maps for variable-rate aerial application. Therefore, remote sensing, spatial statistics, and variable-rate control technologies are all necessary ingredients for a precision aerial application system. This paper will discuss the current state of the above three areas, examine several current trends, and conclude with suggestions for future development.

\section{Current status}

\subsection{Remote sensing}

With an increasing population and a commensurate need for increasing agricultural production, there is an urgent need to improve management of agricultural resources. Satellite and aerial remote sensing technologies have advanced rapidly in recent years and have become effective tools for site-specific management in crop protection and production. Many satellite companies provide satellite imagery data at different spatial, spectral and temporal resolutions for use in precision agriculture. Repeated satellite imagery allows for dynamic crop development monitoring and yield forecasting. Earth-observing satellite systems, such as Landsat systems (NASA - National Aeronautics and Space Administration, Washington, DC), have an advantage for large-scale analysis at regional levels but are limited in spatial resolution. High-resolution satellite systems, such as IKONOS (GeoEye, Dulles, Virginia) and QuickBird (DigitalGlobe, Longmont, Colorado), have been available in recent years, but scheduling these systems for appropriate bands, location of flight, proper altitude, and time of acquisition is difficult. Compared with satellite-based systems, airborne remote sensing systems offer a flexible, do-it-yourself platform for acquiring high quality and high-spatial resolution imagery when atmospheric, environmental and solar conditions are acceptable.

One platform that carries remote sensing instruments is the airborne remote sensing system. There are many usable platforms ranging from helicopters, Unmanned Airborne Vehicles (UAVs) to fixed-wing aircraft. Remote sensing instruments include digital cameras, CCD cameras, video cameras, hyperspectral cameras, multispectral cameras and thermal-imaging cameras. Hyperspectral imaging is part of a class of techniques commonly referred to as spectral imaging or spectral analysis. Hyperspectral imaging and multispectral imaging are related but are usually distinguished by the number of spectral bands. Multispectral data contains from several to tens of spectral bands. Hyperspectral data contains dozens to hundreds of bands. However, hyperspectral imaging may be best defined by the manner in which the data are collected. Hyperspectral data cover a set of contiguous spectral bands (usually by one sensor). Multispectral data comprise a set of optimally chosen spec- tral bands that are typically not contiguous and can be collected from multiple sensors. Use of aerial hyperspectral remote sensing in agriculture has been steadily increasing during the past decade (Goel et al., 2003; Yang et al., 2004, 2009; Jang et al., 2005; Uno et al., 2005; Zarco-Tejada et al., 2005). Compared with hyperspectral systems, multispectral systems are much less expensive and are less data-intensive. Airborne multispectral systems are cost-effective and a good source of crop, soil, weed or ground cover information for agricultural application and production (Moran et al., 1997; Senay et al., 1998; GopalaPillai and Tian, 1999; Yang and Anderson, 1999; Yang and Everitt, 2002; Pinter et al., 2003; Dobermann and Ping, 2004; Huang et al., 2008; Inman et al., 2008; Yang et al., 2009; Lan et al., 2009; Zhang et al., 2009).

In practical applications of airborne remote sensing, different types of multispectral imaging systems have been adopted based on economic and technical feasibilities. Here, we limit our discussion to an aircraft platform with two camera systems, which include a low-cost ADC (Agricultural Digital Camera) and a relatively expensive and high-performance multispectral camera.

\subsubsection{ADC camera}

The Tetracam ADC camera (Tetracam, Inc., Gainesville, FL) is equipped with a 3.2-megapixel CMOS (Complementary Metal-Oxide-Semiconductor) sensor $(2048 \times 1536$ pixels $)$ or a 5.0 megapixel CMOS sensor $(2560 \times 1920$ pixels $)$. It has green, red and near-infrared (NIR) sensitivity with bands approximately equal to Landsat Thematic Mapper 2, Thematic Mapper 3 and Thematic Mapper 4 bands, which fall in the $520-600 \mathrm{~nm}, 630-690 \mathrm{~nm}$, and $760-900 \mathrm{~nm}$ wavelengths. Band information provide data needed for extraction of vegetation indices such as NDVI, SAVI, canopy segmentation and NIR/Green ratios. Standard global positioning system (GPS) data capture from an external receiver adds positioning data to the images. The camera weighs 640 grams with 8 AA alkaline batteries. The 3.2-megapixel ADC fitted with an $8.5 \mathrm{~mm}$ lens is able to achieve a $0.5 \mathrm{~m} /$ pixel ground resolution at $1340 \mathrm{~m}$ (4400 ft) AGL (Above Ground Level). The current cost of the Tetracam ADC camera in 2009 is about $\$ 5000$.

Currently a proprietary software package, PixelWrench2, is used to work with the Tetracam ADC camera to manage and process ADC images. Another proprietary software package, SensorLink, provides a GPS waypoint triggering application enabling camera triggering at pre-defined waypoints.

The ADC cameras are portable and can be used on fixed-wing aircraft such as the single-engine Cessna 210 (Cessna Aircraft Company, Wichita, Kansas), the Air Tractor 402B (Air Tractor, Inc., Olney, Texas), and the UAV (Unmanned Autonomous Vehicle) helicopter such as Rotomotion SR 20 (Rotomotion, LLC, Charleston, South Carolina) with limited payload.

\subsubsection{Geospatial systems MS 4100 camera}

The MS 4100 camera (Geospatial Systems, Inc., West Henrietta, New York) is a multispectral 3-CCD (Charge-Coupled Device) Color/CIR (Color Infrared) digital camera. It provides a digital imaging quality with a 1920 (horizontal) $\times 1080$ (vertical) pixel array per sensor and $60^{\circ}$ wide field of view with a $14-\mathrm{mm}, f / 2.8$ lens. Color-separating optics work in concert with a large-format progressive scan CCD sensors to maximize resolution, dynamic range, and field of view. The MS 4100 camera is available in two spectral configurations: RGB (Red Green Blue) for high quality color imaging and CIR for multispectral applications. The camera images the four spectral bands from 400 to $1000 \mathrm{~nm}$, and acquires separate red (660-40 $\mathrm{nm}$ bandwidth), green (540-40 nm bandwidth), and blue (460-45 $\mathrm{nm}$ bandwidth) image planes. The camera provides composite color images and individual color plane images. It is also able to acquire and provide composite and individual plane images from red, green, and NIR (800-65 nm bandwidth) bands 
that approximate Landsat satellite thematic mapper bands (NASA, Washington, DC; USGS, Reston, VA). The MS 4100 is able to further provide RGB and CIR images concurrently and has the option for other custom spectral configurations. When running the RGB or CIR configuration individually, a base configuration will support any three-tap configuration running at 8 bits per color plane (i.e. 24-bit RGB). Adding a fourth 8-bit tap or outputting 10 bits per color plane requires an additional port with a second cable. The MS 4100 camera configures the digital output of image data with CameraLink standard or parallel digital data in either EIA644 or RS-422 differential format. The camera works with the NI IMAQ PCI-1424/1428 framegrabber (National Instruments, Austin, Texas). With the software DTControl-FG (Geospatial Systems, Inc) and the CameraLink configuration, the camera system acquires images from the framegrabber directly from within the DTControl program. The current cost of the MS 4100 camera is about $\$ 20,000$.

In practical use of the camera on aircraft, operation of the camera would require a technician to control imaging and any ancillary control functions. This is somewhat impractical for small agricultural airplanes as the pilot cannot operate the camera effectively and fly the airplane simultaneously. Control automation is necessary of the multispectral camera is necessary in order to reduce labor required and maintain consistency of camera operation. Based on the needs in agricultural research and applications, the TerraHawk camera control system (TerraVerde Technologies, Inc., Stillwater, Oklahoma) is commercially available and is being integrated to automate the operation of the MS 4100 camera with: (1) Dragonfly ${ }^{\mathrm{TM}}$ software to control the operation of the camera, especially to trigger the camera based on the field shapefile polygon with GPS receiver; (2) a gimbal controller to stabilize and control the camera for roll, pitch, and yaw aircraft rotations during flight.

Huang et al. (2009) concluded that the Tetracam camera in its present state is more suitable for slower moving platforms that can fly close to the ground, such as the UAV; the MS 4100 imaging system worked very well being mounted on an agricultural aircraft like the Air Tractor 402B. Huang et al. (2008) and Lan et al. (2009) have demonstrated the capability and performance of the MS 4100 airborne imaging system for crop pest management.

Such multispectral instruments typically capture imagery that can be related to relative radiance in the visible and near infrared regions. However, all remote sensing measurements can be affected by variable ground conditions, such as plant architecture, canopy characteristics, crop row orientation and coverage, and background soil properties. All of these ground conditions can contribute towards spatial variability within the field and between fields. Sometimes aerial remotely sensed data alone cannot capture all the information required. Data from imagery, ground-truth measurements, and spatial analysis together allow for a more complete understanding of a field's spatial complexity.

\subsection{Spatial statistics}

The techniques of spatial statistics were first developed and formalized in the $1950 \mathrm{~s}$. Recently, with the development of GIS, spatial statistics have drawn considerable attention and have been widely applied in spatial data modeling and analysis for natural sciences such as geophysics, biology, epidemiology and agriculture. There have been numerous studies demonstrating the benefits of spatial analysis to agricultural management. Stein et al. (1997) emphasized the use of spatial analysis in reducing production risks and in formulating variable resource allocation. In a case study to model spatially varied yield monitor data for corn nitrogen response, Bongiovanni and Lowenberg-DeBoer $(2000,2002)$ determined that spatial regression analysis of yield monitor data could be used to estimate the site-specific crop nitrogen response needed to fine tune variable-rate fertilization strategies for maize and soybean.
Lambert and Lowenberg-DeBoer (2003) demonstrated that the spatial econometric, geostatistical approach and spatial trend analysis offered stronger statistical evidence of spatial heterogeneity of nitrogen response than the ordinary least squares or nearest neighbor analysis. Yao et al. (2003) investigated soil nutrient mapping by a co-located co-kriging estimator using soil sampling data and aerial hyperspectral image. Misaghi et al. (2004) developed a model to predict strawberry yield using aerial images, soil parameters, and plant parameters. Bajwa and Mozaffari (2007) tested various spatial models in analysis of the variations in GNDVI (Green Normalized Difference Vegetative Index), a vegetative index derived from aerial remote sensing data in the Visible and NIR (VNIR) regions, in response to nitrogen treatments and petiole nitrate content.

Overall, remote sensing imagery data and spatial statistical methods can provide valuable and complete information in the site-specific management. This information can be used to produce an application map and support aerial variable-rate application.

\subsection{Variable-rate aerial application}

If agricultural aircraft offer a different view of remote sensing, then precision agriculture takes aerial application to new heights. Several types of precision agriculture technologies that assist aerial applicators include GPS, GIS, soil sampling, yield monitoring, nutrient management field mapping, aerial photography, and variable-rate application technology.

Moran et al. (1997) presented an infrastructure that holds promise for incorporating aircraft remote sensing technology into precision crop management. In the first stage, images are acquired and processed to values of surface reflectance and registered to field coordinates. In the second stage, these images are converted to physical crop and soil information. In the third stage, this distributed information about crop and soil conditions is interpreted to produce maps of management units for variable-rate material application. Variable-rate technology is focused on applying pesticides, herbicides, soil amendments, plant harvesting aids and fertilizers at various rates and at specific locations. Aerial application maps are created with variable rates customarily in GIS and then converted to prescription format by software supplied by the airplane's guidance system manufacturer. The variable-rate system uses preloaded "prescription maps" to change flow rates through the field depending on where the application is needed most, least, or where it should not be used at all.

There are two components in a variable-rate aerial application system: GPS and Variable Flow control system. In today's market, one manufacturer, Hemisphere GPS of Calgary, AB, Canada, has developed the Satloc M3 and acquired the Del Norte Flying Flagman. For liquid applications, the Aerial Ace and IntelliFlow (compatible with both Hemisphere Air guidance systems) automatically apply the proper rate of spray at the proper time using a variable or constant rate. The flow system varies the setting of a flow control valve by responding to changes in ground speed. The Fire/Dry Gate Controller (FDGC) is also a new technology that has been added to the list of products to interface with both the M3 and Flying Flagman. Another new technology that Hemisphere GPS has worked on is the Crescent Receiver. The new receiver gives $20 \mathrm{~Hz}$ capability, which means that a pilots' Lightbar will update 20 times/s. Compared with most technologies that offer 5 or $10 \mathrm{~Hz}$ updating, $20 \mathrm{~Hz}$ updating has the potential for better application accuracy because of the smaller time window within which to make rate changes. There are also other companies that offer similar technologies. AG-NAV Inc.'s popular technology is the AG-NAV 2, which provides the pilot with swath, directional guidance and other navigation information. ADAPCO, Inc., Sanford, FL offers the Wingman ${ }^{\mathrm{TM}} \mathrm{GX}$ and NextStar ${ }^{\mathrm{TM}}$ flow control systems technologies to aerial applicators. Wingman 
GX is a highly advanced precision guidance and recording system that was developed to improve aerial pesticide application accuracy and efficiency by processing real time meteorology onboard the aircraft and providing instantaneous optimization offset distance. The AutoCal II flow controller (Houma Avionics, Houma, LA) can interface with all swath guidance systems. The AutoCal II controls boom flow rate by controlling the spray pump output.

Only recently have agricultural aircraft been equipped to implement variable-rate application to match site-specific needs of the crop. Variable-rate aerial application systems have seen limited use only within the past six years or so, and very little information has been presented on the accuracy of these systems for placement of chemical and response of these systems to changing rate requirements. In addition to variable-rate application, aerial flow control systems must adjust flow properly to accommodate changes in ground speed. Smith and Thomson (2005) evaluated position latency of the GPS receiver used in the Satloc Airstar M3 swath guidance against a known ground position. The flow control portion of the system has been tested for positioning accuracy (Thomson et al., 2009) and improved by comparing measured flow rates and step-change responses to desired flow rate response curves and modifying the control program accordingly (Thomson et al., 2010).

\section{Future directions}

The USDA, ARS conducts research involving GPS-based real time guidance and GIS systems for agricultural aircraft to conserve material and provide a commensurate reduction in deleterious pesticide loading to the environment. As precision agriculture continues to grow, more operators are becoming familiar with these technologies because the demand is growing from farmers. Research continues to be conducted to enhance these technologies and create new technologies for accuracy and efficiency.

\subsection{Real time image processing}

Real time processing of imagery is needed to bridge the gap between remote sensing and variable-rate aerial application. Data analysis and interpretation is one of the most important parts of precision aerial application. Whether collected from airborne images, ground-based sensors and instrumentation systems, human observations, or laboratory samples, data must be analyzed properly to understand cause-and-effect relationships. To develop appropriate prescription maps for variable-rate aerial application, the findings from multispectral aerial images in near real time has been a challenge. The ultimate goal is to develop a user-friendly image processing software system, aiming to analyze the data rapidly from aerial images so that variable-rate spraying can occur immediately after data acquisition.

\subsection{VRT system}

There is limited application for turn-key commercial VRT devices due to their perceived high cost and operational difficulty. An economical and user-oriented system is needed that could process spatially distributed information, and apply only the necessary amounts of pesticide to the infested area efficiently and to minimize environmental damage. Additionally, nozzles are designed to produce optimal droplet size spectra for mitigation of off-target drift and to provide maximum application efficacy. These desired size ranges require the nozzles to operate within proper boundaries of their design pressure. Variable rates called for by the aerial application system might operate these nozzles outside their optimal pressure ranges making their valid use questionable if a wide range of flowrates is required. This would not be a problem for "on-off" variable control.

\subsection{Multisensor data fusion technology}

A key step in successful precision system development is creation of accurate prescription maps for aerial application. Creation of these maps can be assisted by multisensor, multispectral, multitemporal and even multi-resolution data fusion utilizing GIS techniques. The data fusion will be based on new methods for the fusion of heterogeneous data: numerical or measurable (radiometric, multispectral, and spatial information) and symbolic (thematic, human interpretation and ground truth) data. The multisensor data fusion scheme needs to be fully integrated into the system through GIS.

\section{Summary}

Precision aerial application will result in more judicious use of pesticides, thereby satisfying environmentalists, legislators and farmers. Large farms typical of the US and parts of China will benefit greatly though the use of these technologies. Small farmers could use precision agriculture technologies by a cooperative system to urgently deal with some areawide pest management issues. Precision aerial application will allow for the targeting of inputs to specific areas of fields, enabling farmers to remain successful in an increasingly competitive industry.

\section{References}

Bajwa, S.G., Mozaffari, M., 2007. Effect of $\mathrm{N}$ availability on vegetative index of cotton canopy: a spatial regression approach. Trans. ASABE 50 (5), 1883-1892.

Bongiovanni, R.G., Lowenberg-DeBoer, J.M., 2000. Nitrogen Management in Corn Using Site-Specific Crop Response Estimates from a Spatial Regression Model. In: Proceedings of the 5th International Conference on Precision Agriculture, Bloomington, MN. Center for Precision Agriculture, University of Minnesota, St. Paul, MN, 16-19 July 2000.

Bongiovanni, R.G., Lowenberg-DeBoer, J.M., 2002. Economic of nitrogen response variability over space and time: results from the 1999-2001 field trials in Argentina. In: Proceedings of the 6th International Conference on Precision Agriculture, Bloomington, MN, ASA-CSSA-SSSA, Madison, WI, 14-17 July, 2002.

Dobermann, A., Ping, J.L., 2004. Geostatistical integration of yield monitor data and remote sensing improves yield maps. Agron. J. 96 (1), 285-297.

Goel, P.K., Prasher, S.O., Landry, J.A., Patel, R.M., Viau, A.A., Miller, J.R., 2003. Estimation of crop biophysical parameters through airborne and field hyperspectral remote sensing. Trans. ASAE 46 (4), 1235-1246.

GopalaPillai, S., Tian, L., 1999. In-field variability detection and spatial yield modeling for corn using digital aerial imaging. Trans. ASAE 42 (6), 1911-1920.

Huang, Y., Lan, Y., Hoffmann, W.C., 2008. Use of airborne multi-spectral imagery in pest management systems. Agr. Eng. Int. X, Manuscript IT 07010.

Huang, Y., Thomson, S.J., Lan, Y., Maas, S.J., 2009. Multispectral imaging system for Airborne remote sensing to support site-specific agricultural management. In: Proceedings of the 3rd Asian Conference on Precision Agriculture (ACPA), Beijing, China, 14-17 October, 2009.

Inman, D., Khosla, R., Reich, R., Westfall, D.G., 2008. Normalized difference vegetation index and soil color-based management zones in irrigated maize. Agron. J. 100 (1), 60-66

Jang, G.S., Sudduth, K.A., Hong, S.Y., Kitchen, N.R., Palm, H.L., 2005. Relating imagederived vegetation indices to crop yield. In: Proceedings of the 20th Biennial Workshop on Aerial Photography, Videography, and High-Resolution Digital Imagery for Resource Assessment, CD-ROM.

Lambert, D.M., Lowenberg-DeBoer, J.M., 2003. Spatial regression models for yield monitor data: a case study from Argentina. In: American Agricultural Economics Association Annual Meeting, Montreal, Canada, 27-30 July, 2003.

Lan, L., Huang, Y., Martin, D.E., Hoffmann, W.C., 2009. Development of an airborne remote sensing system for crop pest management: system integration and verification. Trans. ASABE 25 (4), 607-615.

Misaghi, F., Dayyanidardashti, S., Mohammadi, K., Ehsani, M.R., 2004. Application of Artificial Neural Network and Geostatistical Methods in Analyzing Strawberry Yield Data. ASAE Paper Number: 041147. ASAE, St. Joseph, MI.

Moran, M.S., Inoue, Y., Barnes, E.M., 1997. Opportunities and limitations for imagebased remote sensing in precision crop management. Remote Sens. Environ. 61 (3), 319-346

Pinter Jr., P.J., Hatfield, J.L., Schepers, J.S., Barnes, E.M., Moran, M.S., Daughtry, C.S.T., Upchurch, D.R., 2003. Remote sensing for crop management. Photogram. Eng. Remote Sens. 69 (6), 647-664. 
Senay, G.B., Ward, A.D., Lyon, J.G., Fausey, N.R., Nokes, S.E., 1998. Manipulation of high spatial resolution aircraft remote sensing data for use in site-specific farming. Trans. ASAE 41 (2), 489-495.

Smith, L.A., Thomson, S.J., 2005. GPS position latency determination and ground speed calibration for the Satloc Airstar M3. Appl. Eng. Agric. 21 (5), 769-776.

Stein, A., Brouwer, J., Bouma, J., 1997. Methods for comparing spatial variability patterns of millet yield and soil data. Soil Sci. Soc. Am. J. 61, 861-870.

Thomson, S.J., Smith, L.A., Hanks, J.E., 2009. Evaluation of application accuracy and performance of a hydraulically operated variable-rate aerial application system. Trans. ASABE 52 (3), 715-722.

Thomson, S.J., Huang, Y., Hanks, J.E., Martin, D.E., Smith, L.A., 2010. Improving flow response of a variable-rate aerial application system by interactive refinement. Comput. Electron. Agr. 73 (1), 99-104.

Uno, Y., Prasher, S.O., Lacroix, R., Goel, R.K., Karimi, Y., Viau, A., Patel, R.M., 2005 Artificial neural networks to predict corn yield from compact airborne spectrographic imager data. Comput. Electron. Agr. 47 (2), 149-161.

Yang, C., Anderson, G.L., 1999. Airborne videography to identify spatial plant growth variability for grain sorghum. Precision Agric. 1 (1), 67-79.
Yang, C., Everitt, J.H., 2002. Relationships between yield monitor data and airborne multispectral multidate digital imagery for grain sorghum. Precision Agric. 3 (4), 373-388.

Yang, C., Everitt, J.H., Bradford, J.M., Murden, D., 2004. Airborne hyperspectral imagery and yield monitor data for mapping cotton yield variability. Precision Agric. 5 (5), 445-461.

Yang, C., Everitt, J.H., Bradford, J.M., Murden, D., 2009. Comparison of airborne multispectral and hyperspectral imagery for estimating grain sorghum yield. Trans. ASABE 52 (2), 641-649.

Yao, H., Tian, L., Wang, G., Colonna, I.A., 2003. Soil Nutrient Mapping Using Aerial Hypersepctral Imaging and Soil Sampling Data - A Geostatistical Approach. ASAE Paper Number: 031046. ASAE, St. Joseph, MI.

Zarco-Tejada, P.J., Ustin, S.L., Whiting, M.L., 2005. Temporal and spatial relationships between within-field yield variability in cotton and high-spatial hyperspectral remote sensing imagery. Agron. J. 97 (3), 641-653.

Zhang, H., Lan, Y., Lacey, R., Hoffmann, W.C., Huang, Y., 2009. Analysis of vegetation indices derived from aerial multispectral and ground hyperspectral data. Int. J. Agric. Biol. Eng. 2 (3), 33-40. 